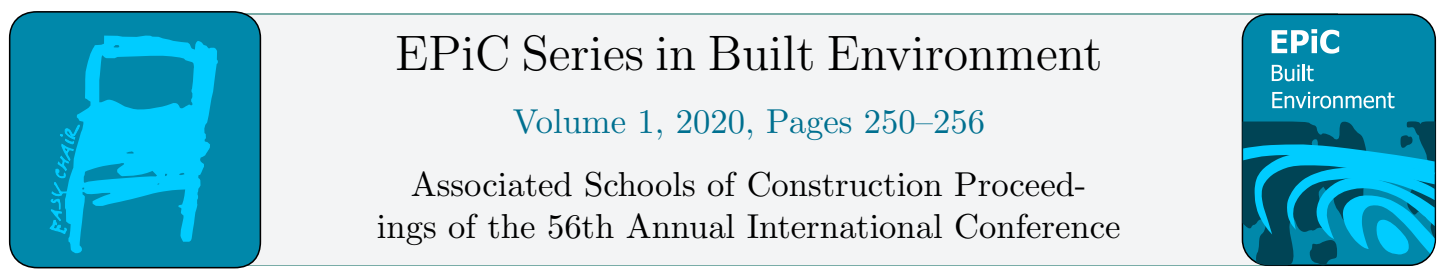

\title{
The Influence of Immediate Urban Surroundings on Energy Performance of Historical Buildings
}

\author{
Onur Dursun ${ }^{1}$; Feyza Durmuslar ${ }^{2}$ and Duhan Olmez ${ }^{2}$ \\ ${ }^{1}$ Liverpool John Moores University, Department of Built Environment, Liverpool, UK \\ ${ }^{2}$ Yasar University, Department of Architecture, Izmir, TURKEY \\ o.dursun@ljmu.ac.uk, feyza.durmuslar@yasar.edu.tr, \\ duhan.olmez@yasar.edu.tr
}

\begin{abstract}
High-density urban areas contain large number of historical buildings whose structures and artistic values are protected by regulations. This restricts the improvements can be made to building envelope to reduce energy demand of historical buildings. Therefore, immediate urban surroundings (IUS) may play a central role on energy performance of historical buildings (EPHB). Yet, literature has provided little or no evidence, so far. To address the gap, the current experimental inquiry aims to test the significance of IUS's influence on the EPHB. To achieve, historical structure in hothumid climate was selected and surveyed thoroughly. Control and intervention cases were considered to measure the influence IUS. The control case corresponds to the former state of IUS; whereas the intervention described as the IUS which includes a recently built office block with reflective glass façade. The numerical result obtained from computational thermal simulations were used for comparison. Accordingly, the increase in heating demand substantially surpassed the decrease in cooling demand for the case under study. Therefore, a significant increase in total energy demand was observed in the presence of intervention. In addition, the energy performance of the individual volumes located in the lower floors presented higher fluctuations due to intervention's shading effect.
\end{abstract}

Key Words: Historical Buildings, Urban Surroundings, Energy Performance, Thermal Simulation, Paired T Test, Experimental Design

\section{Introduction}

Despite extensive effort, the share of energy demand related to building operation has reached to 40\%, increased by 92\% between 1971 and 2014 in Europe (Martínez-Molina, Tort-Ausina, Cho, \& 
Vivancos, 2016). While recent developments in the domain offer numerous solutions to the new building design, assessing and improving energy performance for existing building stock remains to be one of the biggest issues. The problem manifests itself, where significant portion of existing building stock is defined as historic. For example, in Europe, $75 \%$ of the existing building stock is over 50 years old whereas $75 \%$ of these are inefficient in energy performance, causing $36 \%$ of overall CO2 emission (Bastian, Spiekman, \& Troi, 2014). To strictly protect historic and artistic values, relevant regulations introduce significant limitations to the possible changes that can be made to the envelope of historical buildings where the greatest impact can be made.

Relevant literature has proposed new methods, techniques, and technologies that offer energy efficiency improvements for historical buildings. Reducing energy consumption by insulation and building envelope performance (i.e. (Low, 1984; Zheng, Jing, Huang, \& Gao, 2010)), energy efficient design technologies (i.e. (Green, 1982; Kneifel, 2010)), passive design (i.e. (Kreith, 1982; Morrissey, Moore, \& Horne, 2011)) and solar system usage (i.e. (Boyle, 2004; Kalogirou \& Bojic, 2000)) have been active subjects. Since 2000, the major trends have been implementing monitoring techniques to analyze energy performance of historical buildings such as indoor air condition analysis (i.e. (Gysels et al., 2004; Pavlogeorgatos, 2003)), comparison of energy efficiency of historic and new buildings (i.e. (Ealiwa, Taki, Howarth, \& Seden, 2001)), and thermography (i.e. (Grinzato, Bison, \& Marinetti, 2002; Lagüela, Martínez, Armesto, \& Arias, 2011; Ocaña, Guerrero, \& Requena, 2004)). From 2011 and onwards, literature survey suggests a dramatic increase in the number of researches dedicated to economic perspectives (i.e. (Fabbri, Tronchin, \& Tarabusi, 2014)), economic viability analyses (i.e. (Arumägi \& Kalamees, 2014)), rehabilitation (i.e. (De Berardinis, Rotilio, Marchionni, \& Friedman, 2014; Hensley \& Aguilar, 2012)) and proposals of suitable technical solutions for enhancing energy efficiency of historical buildings. The results obtained from the literature survey demonstrated energy performance of historical buildings has been studied predominantly at the building scale largely ignoring the interaction with their urban surroundings.

A significant change that may occur in immediate urban surroundings, may also have a significant impact on the thermal behavior of the historical buildings. However, to the best authors' investigation, no attempt has been made to analyze the impact of a significant change in urban surroundings on the energy demand of historical buildings, so far. Quantitatively demonstrating the influence of such change, if any, can improve and further be fundamental to our decision-making practices in the design of urban areas surrounding historical buildings. To this end, the current study aims to investigate the impact of significant changes in urban surroundings on the energy performance of historical buildings.

\section{Methodology}

To achieve the objectives, two variables were defined. The independent variable corresponds to significant change(s) in the urban surroundings of a given historical building. The current work described significant change in the urban surroundings as extension or thinning of an existing road, erection or demolishment of an adjacent structure, and any major changes caused by a change in the zoning ordinances. Dependent variable corresponded to the energy performance of a given historical building. Energy Use Intensity (EUI) defined as annual energy demand per floor area and measured as $\mathrm{kWh} / \mathrm{m} 2 /$ year, was employed as the metric of the dependent variable. Only heating and cooling loads were considered as these loads constitute a large portion of overall building energy demand. The current work aimed to detect the impact of dependent variable on independent variable while all other things being equal. That is, only the change in urban surroundings were considered while all other factors, which may also have a significant impact on energy performance, were held constant.

In line with definitions and objectives, experimental research design seemed adequate and therefore was adopted in the current work. In this experimental design, first a historical building, whose urban 
surrounding has significantly changed since it was constructed, was selected. Following, the research team conducted an exhaustive historical survey of the selected building. Based on the results, the current work developed computational thermal model, which in turn formed the control case for comparative aims. The plausibility of the simulation results obtained by the control model were validated by comparing results obtained from different simulation engines and interfaces. To analyze the impact of the urban surroundings on the energy performance of the selected historical building, one must determine the significant differences occurred through lifecycle of the selected case. Therefore, a detailed historical survey of the surrounding area was conducted. Once significant changes were detected, they were integrated to the computational thermal model of the control case, which then was labelled as the intervention case. Therefore, the current work successfully established the computational thermal models for the subsequent simulation runs. Last, numeric results obtained from control and intervention cases were compared. Formal test of hypothesis was conducted using Paired t-test statistics.

Selected case used for quantitative inquiry is a historically listed building located in Izmir, Turkey with total floor area of $5,237 \mathrm{~m}^{2}$. The building consists of two attached identical blocks with 4 apartments in every floor. There are 16 apartments being served by the entrances. In the plan scheme, there are volumes and wet areas around the main hall. One single volume has an open balcony area. The building consists of two dwelling types. The first type of dwelling is on the sidelines with 4 volumes whereas the central apartments have 3 volumes. Even though there were changes in the urban surrounding of the selected building, only the intervention which was done within the scope of restoration in 2013 was considered in the current work (Figure 1).

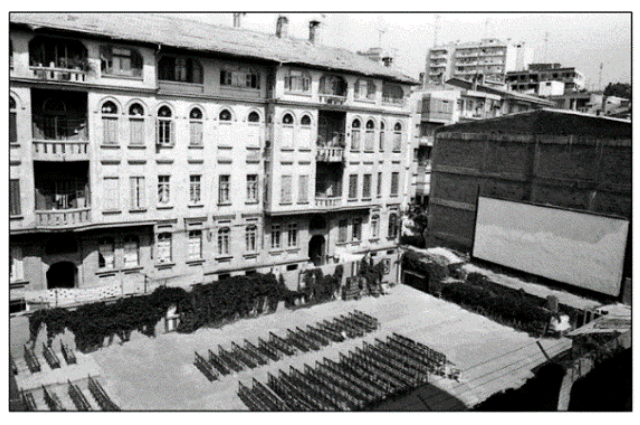

(a)

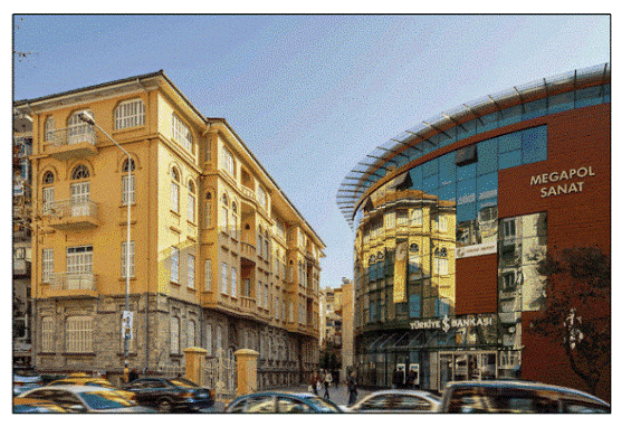

(b)

Figure 1. Selected case and change in its immediate urban surroundings

Computational thermal models were developed in detail based on historical survey. First, watertight virtual (solid) models with no information were appointed on them were created using Rhinoceros 5.0. Next, these models were imported into Grasshopper to define actual volumes with relevant information to form a base for simulations. To reduce the amount of computational power, fenestrations were simplified into rectangle shapes while keeping fenestration ratio and its location as identical to the original design. Finally established models were analyzed using DIVA4 and ArchSIM plugins which work under Grasshopper interface. Using these two instruments in combination enabled the research to calculate the impact of daylight on thermal behavior. Since comparison is central to current inquiry, all energy simulations setting was identical between control and intervention thermal models. After thermal settings were assigned to all building surfaces and volumes, urban surrounding was modeled for two cases: (1) the control case with no adjacent building (2) the intervention case with an adjacent office block (Figure 2). Numerical results obtained by simulation runs were recorded in a Spreadsheet for the subsequent test of hypotheses. 


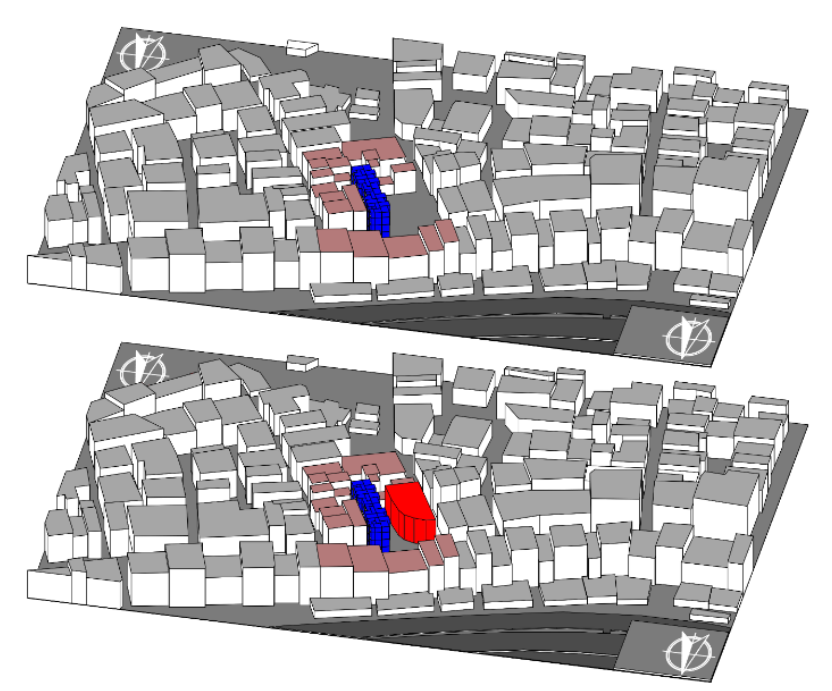

Figure 2. Computational models for control and intervention case

The current study postulated three hypotheses: The first one assumes a significant decrease in EUI cooling value for intervention case; whereas the second and third one postulate a significant increase in EUI heating and total values for intervention case, respectively. As the same spaces were analyzed for both the control and intervention cases, paired t-confidence interval and test procedures seemed adequate to run formal test of hypotheses. Paired $t$ test analyzes the differences between paired observations. The procedure was used to determine if the mean difference for two sample at hand, namely control case - representing the condition at the time the historical building had constructed, against the intervention case - representing the significant change in the urban surrounding, were likely to be different from a reference value. An advantage of analyzing paired observations rather than independent samples is that the variability in the observations is factored out. To reduce the computational cost of thermal and daylight simulations, we purposefully sampled 50 volumes facing west elevation with floor area of $873.6 \mathrm{~m}^{2}$, which corresponds approximately $17 \%$ of the total floor area of selected case

\section{Results and Discussions}

\subsection{Results from thermal simulations}

Table 1

Thermal simulation results from sampled volumes

\begin{tabular}{lrrr}
\hline Energy Demand & $\begin{array}{r}\text { Intervention } \\
\text { (with adjacent building) }\end{array}$ & $\begin{array}{c}\text { Control (no adjacent } \\
\text { building) }\end{array}$ & $\Delta(\%)$ \\
\hline Cooling $(\mathrm{kWh} /$ year) & $8,105.06$ & $8,768.70$ & -7.57 \\
Heating $(\mathrm{kWh} /$ year) & $9,394.35$ & $7,708.52$ & 21.87 \\
Total $(\mathrm{kWh} /$ year) & $17,498.93$ & $16,477.38$ & 6.20 \\
\hline
\end{tabular}

Cooling and heating demand of the intervention case were computed as $8,105 \mathrm{kWh}$, and 9,394 kWh, respectively. For the control case, this corresponded to the total annual energy demand of 17,499 $\mathrm{kWh}$ 
for selected 50 volumes (Table 1). Results of the control case, on the other hand, showed 8,769 $\mathrm{kWh}$ for cooling demand whereas heating demand was calculated as $7,709 \mathrm{kWh}$, corresponding to the total energy demand of $16,477 \mathrm{kWh}$. Results suggests that cooling energy demand of selected volumes in the intervention case is reduced by $7.6 \%$; whereas heating demand in the intervention case is increased by $\% 21.9$. This aggregates to total increase of $6.20 \%$ in energy demand of the intervention case. Since all other variables except the effect of newly built office structure in the adjacent plot were held constant, the current work fulfilled the primary objective of calculating the influence of a change in the urban surrounding on the energy demand of a historical building, successfully.

On observing the simulation results obtained from the selected volumes individually (Figure 3), one can see that the impact of intervention on the energy demand at the south-west facade was higher compared to the volumes in the north-west. On the ground floor, volume 216, 219 and 223 (3 volumes in the same floor at south-west facade) showed significant increase in heating demand while their cooling energy demand was reduced in limited amounts. In comparison, volumes at the same floor yet facing north elevation showed smaller amount of change. This observation further highlighted the shading effect of the intervention building has an impact on the energy performance of the volumes.

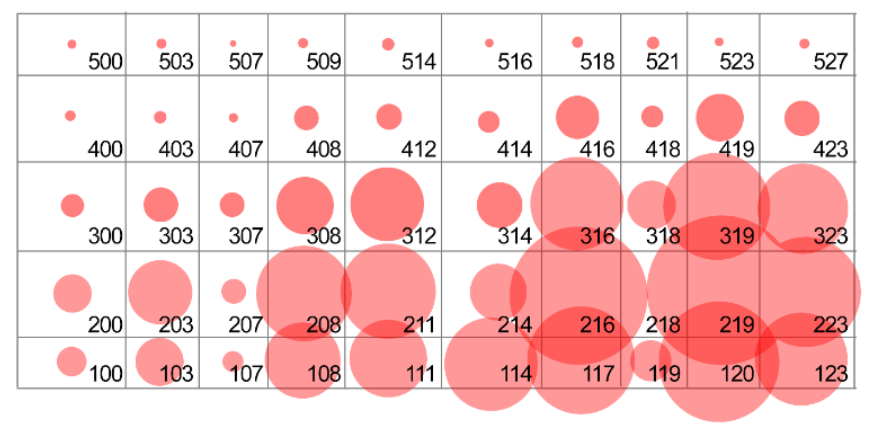

Figure 3. Individual analysis of the volumes - observing on shading effect of the adjacent building

\subsection{Test of hypotheses}

Three hypotheses were postulated in the current work. Based on results obtained from Paired-t test statistics, all null hypotheses were rejected at 5\% significance level. That is, the evidence from the current experimental design was strong enough to suggest that energy demand for cooling in the intervention case is significantly smaller than the control case. Second, one can suggest with $95 \%$ confidence that the heating energy use intensity in intervention case is substantially greater compared to the control case. Last, the findings rigorously demonstrated that total energy use intensity in the intervention case dramatically increased when compared to the control case scenario, considered in the current work. Concluding, based on the evidence obtained from the current experiment design, one may expect a significant increase in the energy demand of a historical building when its immediate urban surroundings were planned while ignoring adequate environmental analysis.

\subsection{Discussion of the results}

Further investigations on the control case showed that open ground area in front of the west side of the building had previously allowed penetration of direct daylight to all volumes facing west in the afternoon. Providing that, afternoon daylight penetrates a building closer to the horizontal axis which in turn influences a deeper penetration of daylight into the building mass, any volume with fenestration facing west benefits from natural heat gain, causing volumes to demand higher amount of cooling energy during summer time. On the other hand, in wintertime exposure to direct sunlight provides heat 
supplement to reduce the demand for heating energy. Considering the results obtained from this experimental study, one can conclude that extra energy demand required for heating in the wintertime significantly exceeded energy savings by cooling demand through the summer season, resulting a significant increase in annual energy demand.

There were discrepancies in floor areas and heights between different volumes. The current work observed especially volumes possessing higher ceiling heights seem to be influenced less compared to the other volumes located at the ground and first floor. This distribution can be tracked in Figure 3 where change in the energy demand was visualized in circular forms. In Figure 3, the diameter of the circular forms was in direct proportion with the change $(\Delta)$ in the energy demand in the sampled volumes. That is, greater the circle is greater the change in energy demand between intervention and control cases. One can see in Figure 3, the distribution of energy demand increase was heterogeneous. Shape, distance, and placement of the adjacent structure next to selected historical building influenced increase in total energy demand for mostly all volumes in the intervention case. Due to the inherit relation between volumes located in the basement floor and their external environment, basement volumes demonstrated the highest difference when compared to other floors. In addition, observed difference was more homogeneous.

On further analyzing the results obtained from different floors, one can observe differences between them as the floor height, glazing placement, and intervention influenced each floor in a different way. Due to the location of the buildings under study, although west façade was exposed to the same daylight, the shadow of the adjacent intervention has changed during the day. That is, upper floors were never subjected to the shading-effect by the intervention case. While basement, ground and first floor posed substantial differences in energy demand over a year, the change in second and third floor energy demand was not significant when compared to others. Lastly, the intervention case required more energy over a year to maintain the identical thermal conditions as the test case

\section{Conclusion}

Adequate assessment of energy performance in historical buildings is crucial and must be integrated to the conservation strategies. However, as historic and artistic values of the historical buildings are under strict protection, limited improvements can be proposed towards increasing energy efficiency to the building itself. This limitation led to reconsider the issue of energy efficiency in historical buildings not only at the structural but also at the urban scale. Hypothetically, a change in immediate urban surroundings may influence the energy demand of the historical buildings. Quantitative demonstration of such influence, if any, can be fundamental to the design of immediate urban surroundings and the assessment of energy efficiency of the historical buildings.

The key findings obtained from the current experimental work rigorously demonstrated an adjacent structure, which was constructed recently, increases total energy demand of the sampled volumes from the selected case, significantly. On observing simulation results, we noted a significant increase in heating demand that substantially surpassed the decrease in cooling demand. Supporting, formal test of hypotheses concludes the influence of a change in immediate urban surrounding on the energy performance of a historical building is statistically significant at 5\% level.

There are limitations to the results of the current work. For instance, the effect of the wind was not considered. As the adjacent building can create new pathways for the predominant north wind for the location under study, it may also have a significant impact on heating demand. Lastly, more experimental, and empirical evidence collected from different locations and cases is required to develop fruitful discussions on the topic under study. 


\section{References}

Arumägi, E., \& Kalamees, T. (2014). Analysis of energy economic renovation for historic wooden apartment buildings in cold climates. Applied Energy, 115, 540-548.

Bastian, Z., Spiekman, M., \& Troi, A. (2014). Energy retrofit of cultural heritage buildings. REHVA $J, 24-27$.

Boyle, G. (2004). Renewable energy. Renewable Energy, by Edited by Godfrey Boyle, pp. 456. Oxford University Press, May 2004. ISBN-10: 0199261784. ISBN-13: 9780199261789, 456.

De Berardinis, P., Rotilio, M., Marchionni, C., \& Friedman, A. (2014). Improving the energyefficiency of historic masonry buildings. A case study: A minor centre in the Abruzzo region, Italy. Energy and Buildings, 80, 415-423.

Ealiwa, M., Taki, A., Howarth, A., \& Seden, M. (2001). An investigation into thermal comfort in the summer season of Ghadames, Libya. Building and Environment, 36(2), 231-237.

Fabbri, K., Tronchin, L., \& Tarabusi, V. (2014). Energy retrofit and economic evaluation priorities applied at an Italian case study. Energy Procedia, 45, 379-384.

Green, M. A. (1982). Solar cells: operating principles, technology, and system applications. Englewood Cliffs, NJ, Prentice-Hall, Inc., 1982. 288 p.

Grinzato, E., Bison, P., \& Marinetti, S. (2002). Monitoring of ancient buildings by the thermal method. Journal of cultural heritage, 3(1), 21-29.

Gysels, K., Delalieux, F., Deutsch, F., Van Grieken, R., Camuffo, D., Bernardi, A., .. . Wieser, M. (2004). Indoor environment and conservation in the royal museum of fine arts, Antwerp, Belgium. Journal of cultural heritage, 5(2), 221-230.

Hensley, J. E., \& Aguilar, A. (2012). Improving Energy Efficiency in Historic Buildings (Vol. 3): Government Printing Office.

Kalogirou, S. A., \& Bojic, M. (2000). Artificial neural networks for the prediction of the energy consumption of a passive solar building. Energy, 25(5), 479-491.

Kneifel, J. (2010). Life-cycle carbon and cost analysis of energy efficiency measures in new commercial buildings. Energy and Buildings, 42(3), 333-340.

Kreith, F. (1982). Solar heating and cooling: active and passive design: CRC Press.

Lagüela, S., Martínez, J., Armesto, J., \& Arias, P. (2011). Energy efficiency studies through 3D laser scanning and thermographic technologies. Energy and Buildings, 43(6), 1216-1221.

Low, N. M. (1984). The Degradation of thermal insulating mineral fibers. Journal of thermal insulation, 8(2), 116-126.

Martínez-Molina, A., Tort-Ausina, I., Cho, S., \& Vivancos, J.-L. (2016). Energy efficiency and thermal comfort in historic buildings: A review. Renewable and Sustainable Energy Reviews, 61, 7085.

Morrissey, J., Moore, T., \& Horne, R. E. (2011). Affordable passive solar design in a temperate climate: An experiment in residential building orientation. Renewable Energy, 36(2), 568-577.

Ocaña, S. M., Guerrero, I. C., \& Requena, I. G. (2004). Thermographic survey of two rural buildings in Spain. Energy and Buildings, 36(6), 515-523.

Pavlogeorgatos, G. (2003). Environmental parameters in museums. Building and Environment, 38(12), 1457-1462.

Zheng, G., Jing, Y., Huang, H., \& Gao, Y. (2010). Application of improved grey relational projection method to evaluate sustainable building envelope performance. Applied Energy, 87(2), 710720. 